\title{
Effects of Exercise Prescription on Performance and Participation Motivation for Older Adults during the Functional Physical Fitness Program: A Case Study on Local Nursing Home Resident
}

\author{
Pin-Yu, $\mathbf{W u}{ }^{*}$ \\ Department of Adult and Continuing Education, National Chung-Cheng University, Chiayi, Taiwan,
}

Taiwan, R. O. C.

\begin{abstract}
*Corresponding Author: Pin-Yu, Wu, Department of Adult and Continuing Education, National ChungCheng University, Chiayi, Taiwan, Taiwan, R. O. C.
\end{abstract}

\begin{abstract}
:
Purpose: The purpose of present study attempted to examine the effects of exercise prescription on performance and participation motivation for older adults during the functional physical fitness program.

Methods: A qualitative research on questionnaire with semi-structured interview on each participant was delivered in this study. Participants were recruited by the SOF test and screening of the local nursing home resident who had been purposed sampling in the early stage of the frailty. Total 30 older adults (average 78 years old) enrolled in the exercise prescription of functional physical fitness and mental training program (5 days each week).

Results: Results revealed that older adults build their performance on lower limb muscles strength significantly outscored than prior performance on pretest. This finding does appear to supports the large body of literature from effective exercise prescription positively affects older adult's achievement. In addition, subjects who worked the exercise prescription of instructional module possess better participation motivation, including appropriate and simple, safety, self-efficacy and satisfaction.
\end{abstract}

Conclusion: The conclusion of this study indicate that the instructional functional fitness mental training program can successfully increase older adults' performance and motivation by employing systematically instructional design.

Keywords: Exercise Prescription, Functional Fitness, Participation Motivation, Older Adults

\section{INTRODUCTION}

As the elderly population is increasing, the issue of "agedness and weakness" has been taken seriously and widely studied (ACSM, 2017; Huang, Wei, \& Cheng, 2010; Lee, 2012). Key features of debilitating include weight loss, sarcopenia, decreased activity, decreased balance and fluency, decreased cognitive function, and impaired nutritional status (Gonçalves, 2019; Jones, \& Rose, 2005 ; Suzuki, et. al., 2017). Patients with debilitating conditions may be affected by decreased physical function, leading to a significant increase in the risk of cardiovascular disease, cancer, falls and mortality. According to the relevant literature, through exercise, it can make the debilitating disease reversible, can improve the condition of debilitating disease, and even reduce the occurrence of sarcopenia. (Del Signore \& Roubenoff, 2017 ; Suzuki \& Bocalini, 2018; Tavassoli et al., 2014 Tarazona-Santabalbina et al., 2016;). Also, there is no ideal treatment for "senile debilitating disease". It is best to prevent and target early exercise prescription for debilitated elderly people. The most effective method is regular exercise or maintain a dynamic life style. State, while slowing the deterioration of "muscle reduction" and reducing the chance of falls (Huang, Wang, \& Lin, 2016; Suzuki, et. al., 2017; Wilson, et. al., 2017).

The three primary objectives of exercise prescriptions for frail older adults are as follows: increased muscle strength, increased cardiovascular endurance, and increased overall physical activity and 
energy expenditure (ACSM, 2017; 2016). The exercise prescription of exercise prescription on this study will adopted a physical and mental fitness program which refers to the design, cognitive function and application of memory system in the process of dropping out of physical activity in the elderly. It not only achieves the enhancement of functional fitness and mental function. And can achieve effective learning outcomes such as cognition, affection, skills and practice. (Gonçalves,

2019, Fried, Tangen, et al., 2001; Heath, \& Stuart, 2002) • It would also be helpful if an individual's activities of daily living and his or balance can be improved via his or her involvement other exercise programs.

In addition, researches have reported that learner characteristics impact performance and motivation in participation behavior studies. Factors such as personality, gender and ability have impacted outcomes in some of the studies. Researchers suggest that individuals' motivational characteristics may influence how they perform in the effective learning environments (Jones., Rose, 2005; Johnson \& Johnson, 1993). Some researchers indicated that exercise participation motivation is the most effectiveness for psychologically development for frail adults (Lin, Zhu et. al. 2017; Jones, \& Rose, 2005; Suzuki \& Bocalini, 2018, Stern, 2012). The theory of participation behavior advocates the importance of immersion into the learner's cultural background and effectiveness of participated in learning. According to the theory of participation motivation, learning is reached through collaborative social interaction and social construction of psychologically wellness (Fernandez-Rio., Sanz, et al., 2016; Johnson \& Johnson, 1993).

As indicated by past studies, multiple complex factors influence in the health life and social construction of psychologically wellness. However, exercise participation behavior can be changed through the use of appropriate learning systems, teaching methods, and interaction strategies (Bodsworth \& Goodyear, 2017; Ferreira, \& Marmeleira, 2017). Social interaction is a strong learning theory that, in addition to meaningful learning for older adults, focuses on balance transposition into real life (ACSM, 2016; Huang, Wang, \& Lin, 2016). Social interaction emphasizes that learning is an important social situation that occurs within everyday cognition and interaction (Johnson \& Johnson, 1993; O’Donoghue, 2016).

Although exercise prescription for older adults were found to improve positive effects of physical fitness and cognitive function (Chan, Tsou, et al., 2017; Wu, Zhou, \& Zhan, 2014), there is a lack of research on the impacts of their exercise participation motivation and that barriers to exercise can be overcome. The purpose of present study attempted to examine the effects of exercise prescription on performance and participation motivation for older adults during the functional physical fitness program. More specifically, the following questions were addressed in this study: (1) Are there significant differences in the posttest performance of older adults on learning condition? (2) Do older adults possess better participation motivation or barriers toward the exercise prescription of instructional module?

\section{METHOD}

\subsection{Participants}

Participants were recruited by the SOF test and screening of the local nursing home resident who had been sampled in the early stage of the debilitating disease. Total 30 older adults (average 78 years old) enrolled in the exercise prescription of functional physical fitness training program (5 days each week). While students in this class are required to participate in one research study during an instructional program, participation in this particular study was not mandatory. Before exercise prescription of study, instructor will explain the purpose of the study, the rights and risks of the subjects, the precautions, and the subject's consent to participate in the instructions and consent. Participants had the option not to participate or withdraw from the study at any time.

\subsection{Materials}

A qualitative research on questionnaire with semi-structured interview on each participant was delivered in this study. Also, this study explores the case study method and uses the observation of the anecdote record to investigate the participation motivation or barriers toward the exercise prescription of instructional module. Materials used in this study were an instructional functional physical fitness lesson, the principle of exercise prescription, an instrument to measure student 
motivation, and a functional physical fitness and mental performance posttest.

\section{The Exercise Prescription of Functional Physical Fitness Program.}

The core program principles and training methods (Huang, Wang, \& Lin, 2016; Rose and Jones, 2005) used in the study was designed to help the older adults build their performance in functional physical fitness. During the practicing stage, participants received immediate feedback in specific skill areas by instructor. This unit is designed for self-instruction and group learning. The content presented in the program consists of five segments: 1) Principles warm-up and cool-down. 2) Flexibility training. 3) Resistance training. 4) Aerobic endurance training 5) Balance and mobility training 6) (Rose and Jones, 2005). The exercise prescription of functional physical fitness training program was delivered during the ten weeks ( 5 days each week). The exercise prescription of training principle was adopted from American College of Sport Medicine (ACSM, 2016). In pilot studies, the instructional lesson was reviewed and revised by two content experts and three functional physical fitness instructors. The instructional lesson was formatively evaluated using older adults of the target group, and was revised into its final form for instructional unite.

\section{The Principle of Exercise Prescription}

According to America College of Sport Medicine (ACSM, 2016), the exercise prescription guidelines for each item are shown in following guidelines.

1) Muscle strength (Sets of 12-15 repetitions for each muscle group)

- Objective: Increase upper limb and lower limb muscle strength

- Increase or prevent loss of lean tissue

- Reduce risk of falling

- Improve balance

- Improve ability to carry out activities of daily living

2) Muscular endurance (Progress slowly from one to two sets)

- Increase endurance and functional abilities

- Improve ability to carry out activities of daily living

3) Physical activity (Sessions of 30-60 minutes - gradually increase)

- Increase energy expenditure

- Improve ability to carry out activities of daily living

4) Activities of daily living (slowly be increased 3-5 days every week)

- Improve ability to carry out activities of daily living

- Improve quality of life

5) Balance (balance exercises 3-5 days every week)

- Improve balance

- Reduce risk of falling

- Improve quality of life

\section{> The Instructional Materials Motivation Scale.}

Motivation was measured using this scale including simple, safety, self-efficacy and Satisfaction (Huang, Wang \& Lin, 2017). This scale consists of six questions that measure student perceptions toward the motivational characteristics of instruction in the affective area of satisfaction. A five-point Likert scale is used to answer the questions. The Cronbach alpha internal-consistency relationship reliability estimate of this scale is .80 .

The semi-structured interviews outline was following table 2: 
1. Do you think this exercise was satisfying?

2. Do you think motor practice and skill were simple?

3. Would like to participate in activity?

4. Did not enjoy activity or difficult

5. Do you feel safety to complete activity?

6. Do you have confidence in the motor performance?

\section{Posttest.}

Tenth weeks after completing the instruction and practicing, all participants received an SOF Frailty index (Study of Osteoporotic Fracture) of posttest. This posttest unit was adapted according to the standard frailty test (Fried, et al., 2001; Rikli, \& Jones, 2001). The posttest was based on multicomponent of physical exercises exercise prescription program on functional fitness and mental. Data from the pilot studies were used to determine reliability estimates for posttest. Cronbach's alpha method was used to calculate the reliability of the posttest, and was found to have a value of .82.

\subsection{Procedures}

The study was implemented twice a week during a ten-week period. The pretest was administered during the first week. The study consisted of five functional fitness instructional units. In addition, each group was given 30-minutes periods on exercise prescription practicing during the two to ninth week. In the debilitating test section, the doctors who cooperate with the nursing home was hired to assist in the assessment. The instructors of program had a certificate and qualified experiences on teaching functional fitness.

The content of the course is designed according to the American College of Sports Medicine (ACSM, 2016), providing the guiding principle of exercise for the frail elderly. In additional, the safety concerns associated with other diseases and conditions commonly encountered in the frail elderly population for whom exercise should be considered (ACSM, 2016; Heath, \& Stuart, 2002). Upon completion the ninth week of the lesson, a qualitative research on questionnaire and interview on each participant individually on motivation. The posttest was a delivered in the final week of the study.

\section{RESUlts}

\subsection{Performance on Functional Fitness}

Overall analysis of variance results are presented in Table 1 . The results of the performance on functional fitness from $t$ test showed significant promotion among the group. The significant effect on the functional fitness were shoulder joint, hip joint, lower limb muscle strength, and dynamic balance. In Table 2.

Table1. Performance on Functional Fitness

\begin{tabular}{|c|c|c|c|}
\hline category & Pre-test & Post-test & $\Delta(\%)$ \\
\hline Upper limb flexibility & $-13.65 \pm 10.39$ & $-9.67 \pm 9.04$ & 29.18 \\
\hline Lower limb flexibility & $-1.82 \pm 7.30$ & $3.37 \pm 6.64$ & 286.64 \\
\hline Lower limb muscle strength & $16.71 \pm 2.88$ & $17.74 \pm 2.67$ & 6.17 \\
\hline Dynamic balance & $9.22 \pm 1.91$ & $8.33 \pm 1.20$ & -9.89 \\
\hline
\end{tabular}

Note : Achange range $(\%)=[($ postest-pretest $) /$ pretest $] * 100 \%$

Table2. Exercise prescription effects on pre-test and post-test.

\begin{tabular}{|l|l|l|l|l|l|}
\hline category & time & M & SD & $t$ & $p$ \\
\hline \multirow{2}{*}{$\begin{array}{c}\text { Shoulder joint } \\
(\mathrm{cm})\end{array}$} & pre-test & -13.774 & 10.58 & $-5.48^{* * * *}$ & .00 \\
\cline { 2 - 5 } $\begin{array}{c}\text { Hip joint } \\
(\mathrm{cm})\end{array}$ & post-test & -9.86 & 9.33 & & \\
\cline { 2 - 5 } $\begin{array}{l}\text { Lower } \\
\text { muscle }\end{array}$ & pre-test & -1.81 & 7.29 & $-5.44 * * *$ & .00 \\
\cline { 2 - 5 } & post-test & 3.56 & 6.93 & $-2.94 * * *$ & .00 \\
\hline
\end{tabular}


Effects of Exercise Prescription on Performance and Participation Motivation for Older Adults during the Functional Physical Fitness Program: A Case Study on Local Nursing Home Resident

\begin{tabular}{|c|c|c|c|c|c|}
\hline strength ( fre. ) & & & & & \\
\hline \multirow{2}{*}{$\begin{array}{l}\text { Dynamic } \\
\text { balance ( sec. ) }\end{array}$} & pre-test & 9.21 & 1.91 & \multirow[t]{2}{*}{$3.79 * * *$} & \multirow[t]{2}{*}{.00} \\
\hline & post-test & 8.53 & 1.51 & & \\
\hline
\end{tabular}

$\mathrm{N}=30, * * * p<.001$

\subsection{Participation Motivation}

Participation motivation was measured using this scale including simple, safety, self-efficacy and Satisfaction. This scale consists of six questions that measure student perceptions toward the motivational characteristics of instruction in the affective area of motivation was measured using the semi-structured interviews outline. The results revealed that overall analysis of interview showed significantly more positive attitudes on exercise prescription program. The significant effects of interview context were following:

On the first day of class, S5 was sent by all the trainees as the squad leader. At the beginning, they were unwilling to accept it. However, in the future, they were able to assist the venue layout and afterschool finishing of the venue before class, and exerted their strong sense of responsibility and participation. Responsibility and a sense of accomplishment is one of the most moving things this week, and S5 asks for its individual demonstrations, not afraid, and generous performances. S5 believes that serving everyone every day has become a fixed job. As a squad leader, it is incumbent upon him. It obviously helps his learning motivation and self-efficacy, and it also adds to his sense of accomplishment.

S2 informed the instructors that there were teachers who had been happy singing at 8 o'clock in the morning, and said that they were very looking forward to the class, and the frequency of interaction between the participants did increase. At the same time, S1I was given a leave of absence today, especially for other students. It can be seen that mutual concern and care are emerging at any time. And after eight weeks of interactive courses, in addition to the increase in the frequency of their interactions during class, after class, they will also automate the chat discussion on the topic of the day, and even the self-motivated students can help others.

S5, S9 squat action is easy and simple, after the action can be guided to the standard from 6 seconds, continuous improvement every day and maintain the action for 20 seconds, S5 said the foot will be very acidic, and will sweat.

Because the $S 8$ is hard to listen to, it needs the teaching team to follow the demonstration for the micro-sports action. It still had confidence to try and to complete it. From the inoperable action to the 22 seconds, it is even more touching. It is always in the week after a few weeks. Will be spontaneous exercise and very serious.

S2 and S11 need to help others to use the four-legged walker to walk and walk. In the later stage, they can walk 15 steps. Both of them said that they hope that they will not take wheelchairs and will find time to practice their leg strength and get out of the wheelchair as soon as possible.

S2 and S11 need to help others to use the four-legged walker to walk and walk. Today, they can walk 6 steps each. Both of them said that they hope that they will not take wheelchairs and will have confidence to get there and to practice their leg strength and get out of the wheelchair as soon as possible.

S1 is nearly 90 years old and has a lower limb muscle weakness. She uses a four-legged chair to stand and walk. With the help of medical staff, he can walk slowly for a few steps. She has a strong reaction and hopes to stand up and walk around the scene. The students who grew up were very encouraged.

The first five weeks of S8 were almost expressed in body language. They didn't open their mouths. The teaching team also thought that his observation was very strong, but in the sixth week, he could already express his feelings and even thank the teaching team.

\section{Conclusion And Suggestions}

The purpose of present study attempted to examine the effects of exercise prescription on performance 
and participation motivation for older adults during the functional physical fitness program. A questionnaire with semi-structured interview on each participant was delivered in this study. Also, this study explores the case study method and uses the observation of the anecdote record to investigate the participation motivation or barriers toward the exercise prescription of instructional module. Results revealed that older adults build their performance on lower limb muscles strength significantly outscored than prior performance on pretest.

The most important finding to emerge from this study was that instructional method interacted with design on the functional fitness and program and exercise prescription guidelines to have an effect on performance for older adults. The results of this study lend support to others who indicate that effective exercise prescription positively affects older adult's achievement and attitude. One possible explanation for this finding is that older adults with a low function of fitness or cognitive impairment are more likely to be motivated and learn when instruction is presented via systematically instructional design.

In addition, subjects who worked the exercise prescription of instructional module possess better participation motivation, and reported greater satisfaction. One plausible explanation for the results obtained is that older adults in groups interaction feel more supported from instructor and satisfied with program design. This study has some implications for those who design instruction for older adults. Instructional functional fitness mental training program can successfully increase older adults' performance and motivation by employing systematically instructional design. The current study suggests that designers should recognize safety concerns associated with other diseases and conditions commonly encountered in the frail elderly population for whom exercise should be considered.

Future studies should also examine the practical setting of intervention is programmed into multicomponent exercise for functional fitness and cognitive benefits for older adults. The relatively short duration of the treatment and the effect of instructional control may have influenced the outcomes. Extending the experimental time for overall instruction could produce different results for participation motivation and performance. Further research should identify critical affective factors under which effective exercise prescription can be generated on the domain of functional fitness and mental training for older adults.

\section{REFERENCES}

[1] American College of Sports Medicine. (2017). ACSM's Exercise Testing and Prescription.

[2] American College of Sports Medicine. (2016). ACSM'S exercise for older adults. Philadelphia, U. S. A.

[3] Bodsworth, H. \& Goodyear, V. A. (2017). Barriers and facilitators to using digital technologies in the Cooperative Learning mod el in physical education, Physical Education and Sport Pedagogy.

[4] Chan, D. C. D., Tsou, H. H., Chang, C. B., Yang, R. S., Tsauo, J. Y., Chen, C. Y., \& Hsiung, C. A. (2017). Integrated care for geriatric frailty and sarcopenia: a randomized control trial. Journal of cachexia, sarcopenia and muscle, 8(1), 78-88.

[5] Del Signore, S., \& Roubenoff, R. (2017). Physical frailty and sarcopenia (PF\&S): a point of view from the industry. Aging clinical and experimental research, 29(1), 69-74.

[6] Ferreira, S., \& Marmeleira, J. (2017). Physical activity and functional fitness in older adults with cognitive impairment. In Motricidade; Book of Abstracts of the International Congress of Exercise and Health, Sports and Human Development, CIDESD (Vol. 13, No. 1, pp. 174-175).

[7] Fried, L. P., Tangen, C. M., Walston, J., Newman, A. B., Hirsch, C., Gottdiener, J., et al. (2001). Frailty in older adults: evidence for a phenotype. Journals of Gerontology Series A-Biological Sciences \& Medical Sciences, 56(3), M146-156.

[8] Heath, J.M. \& Stuart, M.R. (2002). Prescribing exercise for frail elders,JABFP, May-June, Vol. 15 No. 3.

[9] Fernandez-Rio, J., Sanz, N., Fernandez-Cando, J., \& Santos, L. (2016). Impact of a sustained cooperative learning exercise prescription on student motivation. Physical Education and Sport Pedagogy.

[10] Gonçalves, I. O., Bandeira, A. N., Coelhojunior, H. J., Aguiar, S. S., Camargo, S. M. Asano, R. M. \& Junior, M. L. (2019). Multicomponent Exercise on Physical Function, Cognition and Hemodynamic Parameters of Community-Dwelling Older Adults: A Quasi-Experimental Study. Published online 2019 Jun 20. doi: 10.3390/ijerph16122184.

[11] Huang, C. Y., Wei, H. C. \& Cheng, H. C. (2010). Relationship between regular exercise in older adults and successful aging: Model construction and indicator development and application. NSC Project Report. 
[12] Huang, C. Y., Wang, H. H. , \& Lin, M. J. (2016). The effects of functional physical and mental fitness platform for active ageing. Annual global report on Innovation in Active, Healthy and Smart Ageing Sector. Beijing Science \& Technology Publishing Press.

[13] Johnson, D. W., \& Johnson, R. T. (1993). Cooperative learning and feedback in technology-based instruction. In Dempsey, J., \& Sales, G. C. (Ed.), Interactive instruction and feedback. Englewood Cliffs, NJ: Educational Technology Publications.

[14] Jones, C. J., Rose, D. J. (2005). Physical Activity Instruction of Older Adults. Champaign, IL: Human Kinetics.

[15] Lee, S. F., Liu, S. Y. (2017). Functional fitness of the elderly (1 version of 6 brushes). Taipei City: Huadu Culture.

[16] Lin Z. Y, Zhu Qili, Zhang Junru, Lan Shouren, Xie Wei (2017). Correlation analysis of exercise time, body mass index and cognitive dysfunction in the elderly. Journal of Physical Education, 50(S), 33-45.

[17] Ng, T. P., Feng, L., Nyunt, M. S. Z., Feng, L., Niti, M., Tan, B. Y., .. \& Yap, K. B. (2015). Nutritional, physical, cognitive, and combination exercise prescriptions and frailty reversal among older adults: a randomized controlled trial. The American journal of medicine, 128(11), 1225-1236.

[18] Rikli, R. E., \& Jones, C. J. (2001). Senior fitness test manual. Champaign, IL: Human Kinetic.

[19] Suzuki, Makizako, Doi, Park, Lee, Tsutsumimoto, Umemura1, Maki1, Shimada. (2017). CommunityBased Exercise prescription for Prevention of Dementia in Japan, The Journal of Prevention of Alzheimer's Disease - JPAD. Volume 2, Number ,1-6.

[20] Suzuki, F. S. \& Bocalini, D. S. (2018). Effets of a Multicomppnent Exercise Program on the Functional Fitness in Elderly Women. CICLINICAL EXERCISE MEDICINE • Rev Bras Med Esporte 24 (01) https://doi.org/10.1590/1517-869220182401179669

[21] Stern Y. (2012). Cognitive reserve in ageing and Alzheimer's disease. Lancet, Neurol;11:1006-12. Collette F, Van der Linden M. (2002). Brain imaging of the central executive component of working memory. Neurosci Biobehav, Rev;26:105-25.

[22] Tarazona-Santabalbina, F. J., Gómez-Cabrera, M. C., Pérez-Ros, P., Martínez-Arnau, F. M., Cabo, H., Tsaparas, K., ... \& Viña, J. (2016). A multicomponent exercise exercise prescription that reverses frailty and improves cognition, emotion, and social networking in the community-dwelling frail elderly: a randomized clinical trial. Journal of the American Medical Directors Association, 17(5), 426-433.

[23] Tavassoli, N., Guyonnet, S., Van Kan, G. A., Sourdet, S., Krams, T., Soto, M. E., ... \& Cestac, P. (2014). Description of 1,108 older patients referred by their physician to the "Geriatric Frailty Clinic (GFC) for Assessment of Frailty and Prevention of Disability" at the gerontopole. The journal of nutrition, health \& aging, 18(5), 457-464.

[24] WHO, A. A. (2002). A policy Framework. Geneva, Switzerland: World Health Organization.

[25] Wilson D, Jackson T, Sapey E, Lord J. M. (2017). Frailty and sarcopenia: The potential role of an aged immune system. Ageing Res Rev. Jul; 36:1-10.

[26] Wu Yazhen, Zhou Yijun, Zhan Dingzheng (2014). Literature review - sarcopenia and debilitation. Internal Medicine, 25, 131-136.

\section{AUTHOR'S BIOGRAPHY}

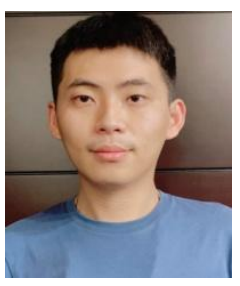

Pin-YuWu, is a candidate student of Ph. D program in Department of Adult and Continuing Education, National Chung-Cheng University, Chiayi, Taiwan, Taiwan, R. O. C.Wu's field of expertise lies in sports, health and recreation management, physical activity instruction of older adults, and the design of sport management for active-aging learners.

Citation: Pin-Yu, Wu. "Effects of Exercise Prescription on Performance and Participation Motivation for Older Adults during the Functional Physical Fitness Program: A Case Study on Local Nursing Home Resident" International Journal of Humanities Social Sciences and Education (IJHSSE), vol 8, no. 8 2021, pp. 113-119. doi: https://doi.org/10.20431/2349-0381.0808010.

Copyright: (C) 2021 Authors. This is an open-access article distributed under the terms of the Creative Commons Attribution License, which permits unrestricted use, distribution, and reproduction in any medium, provided the original author and source are credited. 